\title{
A ORGANIZAÇÃO RETÓRICA DAS SEÇÕES DE JUSTIFICATIVA DE PRÉ-PROJETOS DE PESQUISA
}

\author{
Francisco ALVES FILHO ${ }^{1}$ \\ Meryane Sousa OLIVEIRA ${ }^{2}$
}

\begin{abstract}
Resumo: O artigo em tela tem como objetivo identificar e descrever, através de pistas linguísticas e da organização textual, a organização retórica da seção Justificativa do gênero pré-projeto de mestrado, dos Programas de Pós-graduação em Letras/Linguística e História do Brasil da Universidade Federal do Piauí, submetidos à seleção no ano de 2015, procurando identificar se há singularidades em cada uma delas. A análise foi feita usando as abordagens propostas por Swales (1990), Alves Filho e Alexandre (2015) e Jucá (2006). Foram selecionados 11 pré-projetos de pesquisa de mestrandos do curso de pós-graduação em História do Brasil e 11 pré-projetos de pesquisa de mestrandos do curso de pós-graduação em Letras/Linguística da UFPI, totalizando 22 seções de justificativa. Em linhas gerais, os resultados indicam que "Apresentando objetivos da pesquisa" é o passo retórico mais expressivo no corpus das duas áreas analisadas. Além disso, foi possível verificar que os mestrandos de História optam, sobretudo, por organizar esta peça genérica a partir do levantamento de problemas, enquanto os mestrandos iniciantes de Letras/Linguística, por outro lado, preferiram destacar os resultados positivos que suas investigações poderão trazer para a sociedade e a comunidade acadêmica.
\end{abstract}

Palavras-chave: Gêneros de pesquisa. Organização retórica. Seção Justificativa. Préprojeto.

\footnotetext{
${ }^{1}$ UFPI - Universidade Federal do Piauí - Coordenação de Letras Vernáculas e Programa de Pós-graduação em Letras. Teresina - Piaú - Brasil.64049-550 - chicofilhoo@gmail.com

${ }^{2}$ UFPI - Universidade Federal do Piauí - Programa de Pós-graduação em Letras. Teresina - Piauí - Brasil. 64049-550 - meryaneoliveira@yahoo.com.br
}

http://dx.doi.org/10.21165/gel.v14i1.1436 


\section{Introdução}

A pós-graduação é uma etapa importante na formação de profissionais que buscam constante aprimoramento na carreira. O mestrado, dentre essas possibilidades, exige como uma de suas etapas de ingresso a apresentação de um pré-projeto relacionado a uma linha de pesquisa. Assim, um pesquisador que queira concorrer a uma vaga precisa lidar com as demandas da área, que incluem, no geral, a produção de um pré-projeto. Para a escrita desse gênero acadêmico, os proponentes devem se apropriar dos aspectos retóricos das várias seções que o compõem, pois são eles que fornecem, de antemão, as informações necessárias para o julgamento da instituição avaliadora. A seção de justificativa, pelo fato mesmo de justificar a proposta de pesquisa e potencialmente congregar passos retóricos com clara função argumentativa, reveste-se de um tema bastante relevante na área de estudos de gêneros acadêmicos. Ademais, a compreensão de como iniciantes na pós-graduação concebem estratégias de escrita de pré-projetos pode ser bastante relevante para orientar práticas de ensino de escrita acadêmica que tomem por parâmetro necessidades reais de aprendizagem. No contexto brasileiro, isso se torna ainda mais crucial em face da escassez de manuais de metodologia e de escrita de projetos que sejam fundamentados em necessidades de escrita de áreas e subáreas do conhecimento.

A partir de uma análise comparativa entre pré-projetos de mestrado nas áreas de História e de Linguística, ambos da Universidade Federal do Piauí (UFPI), pretende-se, neste artigo, identificar e categorizar os movimentos e passos retóricos da seção Justificativa do gênero pré-projeto, a partir de uma proposta sugerida por Alves Filho e Alexandre (2015). A opção pelas áreas de Letras e História decorreu da necessidade de se compreender se, em duas áreas de humanidades, há mais convergência ou divergência quanto à organização retórica de uma seção de pré-projeto de pesquisa.

Compreender a composição desse gênero, mediante análise de suas seções, possibilita, sobretudo, depreender aspectos do fenômeno textual-linguístico em funcionamento, vinculando-o às práticas efetivas dos usuários da língua. Por esta razão, faz-se necessário um estudo que evidencie como os usuários organizam a linguagem em situações mais complexas de escrita. 
Este artigo, portanto, buscando entender a organização retórica de uma seção específica, volta-se para uma questão central deste estudo, a saber: O que os passos retóricos identificados revelam sobre a composição da seção justificativa em pré-projetos de mestrado? Em face de tal problemática, objetiva-se identificar e descrever, através de pistas linguísticas e da análise retórica dos dados, os movimentos e passos retóricos da seção Justificativa do gênero pré-projeto de mestrado, buscando reconhecer pontos de convergência e divergência em relação ao modo como pré-projetos de Linguística e História revelam valores sobre a ação retórica de justificar uma pesquisa a nível de mestrado.

\section{Análise de gêneros em contextos acadêmicos}

Pensar os gêneros em uma perspectiva sociorretórica é assumir que eles adquirem significado a partir da situação e do contexto social (MILLER, 2009; DEVITT, 2004). A visão de gênero como ação social volta-se para uma posição em que os estudos de gênero, mais que propor a criação de taxionomias, preocupam-se em enfatizar aspectos sociais e históricos da retórica, procurando convalidar as concepções de gênero e as práticas de uso encetadas pelos sujeitos em seus contextos autênticos (MILLER, 2009).

A intenção dos usuários, os efeitos que querem produzir, associadas ao contexto, compõem a situação retórica visto que "a compreensão de gênero pode ajudar a explicar a maneira como encontramos, interpretamos, criamos e reagimos a textos particulares” (MILLER, 2009, p. 22). Esta visão leva ao reconhecimento de que a prática retórica engloba tanto a substância quanto a forma do gênero e enfatiza a importância de aspectos sociais e culturais de um texto.

Swales (1990), em face de suas preocupações aplicadas ao ensino de escrita, propôs um modelo teórico-metodológico que serviu de base para muitas análises de gêneros acadêmicos em diversos países. Sua proposta centra-se na tese de que o aspecto funcional dos gêneros - encarnado pelos propósitos comunicativos - constitui a racionalidade própria aos textos e, consequentemente, que os aspectos formais e estilísticos decorrem dos propósitos compartilhados pelas comunidades discursivas ${ }^{3}$. Em

\footnotetext{
${ }^{3}$ Swales prefere usar o termo "propósitos comunicativos" em vez de "ação social dos gêneros”, como faz Miller. Entretanto, o que subjaz às preocupações com os propósitos comunicativos se assemelha às
} 
trabalho posterior, Askehave e Swales (2009) reconhecem que o propósito comunicativo é um conceito complexo pelo fato de: a) nem sempre haver consenso entre os especialistas e entre os especialistas e os analistas de gênero acerca de quais sejam efetivamente os propósitos comunicativos de um gênero; b) sujeitos com grande expertise conseguirem imiscuir propósitos particulares em meio aos propósitos mais gerais de um gênero; c) alguns propósitos, embora identificados pelos sujeitos, nunca serem por eles reconhecidos.

Conquanto este reconhecimento da dificuldade analítica imposta pela natureza multifuncional dos propósitos, Askehave e Swales (2009) continuam defendendo a centralidade dos propósitos para a análise de gêneros mas admitem agora dois caminhos metodológicos diferentes: na primeira opção, parte-se da análise da estrutura, conteúdo, estilo e propósito, tendo este último um status provisório. A validação destas categorias dependerá de uma análise contextual feita complementarmente. Na segunda opção, a análise se inicia por uma abordagem etnográfica do contexto de produção do gênero para, na sequência, o pesquisador se voltar à análise textual. Ambas as propostas apresentam um ponto em comum: definir-se o "repropósito” do gênero ao final do processo, ou seja, desvelar os propósitos retóricos que resultam de imbricadas relações entre aspectos textuais, contextuais e retóricos apenas após um complexo trabalho de investigação.

Em termos operacionais, a proposta de Swales ganhou destaque através do Modelo C.a.R.S (Create a Research Space), o qual foi sendo reformulado em várias obras e apresentava como objetivo descrever a organização retórica de gêneros (a rigor, de seções dos gêneros). Neste modelo, uma organização retórica (denominação usada por diversos autores brasileiros, como BEZERRA, 2001; JUCÁ, 2006; BIASI; HEMAIS, 2005) é vista como uma descrição ao mesmo tempo funcional e estrutural de seções de textos, que traduz tendências quanto ao modo como, em determinada comunidade discursiva, seções de textos são organizadas. A organização retórica é descrita em termos de movimentos, que são as unidades retóricas e comunicativas coerentes e recorrentes em lugares previsíveis dos textos, e os passos retóricos, que são as estratégias retóricas particulares reconhecíveis nos textos. Swales (2004, p. 229) ressalta que o movimento (e o passo, sobretudo, acrescente-se) precisa ser concebido como uma unidade flexível do 
ponto de vista de sua realização linguística, dado que sua extensão linguística é bastante variável, podendo ir de uma única oração a todo um parágrafo longo. Contudo, há categorias gramaticais que funcionam como indícios relevantes para o reconhecimento de movimentos e passos. Vale a pena ressaltar que enquanto os passos possuem uma realidade concreta e podem ser efetivamente reconhecidos e localizados nos textos, os movimentos são categorias bem mais abstratas, uma vez que são teoricamente criadas pelos pesquisadores para englobar um conjunto de passos que possuem congruência funcional e retórica.

Em uma versão já renovada de sua pesquisa inicial com introduções de artigos de pesquisa, Swales (1990) chegou ao estabelecimento de três movimentos retóricos para esta seção, os quais são categorizados via metáforas ecológicas: “estabelecer o território”, “estabelecer o nicho”, “ocupar o nicho”. O modelo de Swales, em parte devido a sua praticidade e capacidade de simplificar os relacionamentos complexos entre o caráter pragmático e estrutural dos textos, e também pelo caráter muito sugestivo das metáforas usadas, foi replicado em inúmeros estudos e para várias outras seções e gêneros diferentes: resumo (BIASI-RODRIGUES, 2009), resenha (BEZERRA, 2001), editoriais de jornal (SOUSA, 2004); depoimentos em comunidades de alcóolicos anônimos (BERNARDINO, 2000).

\section{Investigações sobre organização retórica de projetos de pesquisa}

O gênero projeto de pesquisa é pouco estudado no Brasil, a despeito de seu prestígio nos meios acadêmicos, tendo em vista que ele se configura como uma certificação da potencialidade dos pesquisadores para angariar financiamento para suas pesquisas. Pesquisar o gênero projeto de pesquisa se justifica, antes de tudo, pela contribuição que pode fornecer para a própria melhoria das pesquisas, visto que não se é autorizado a fazer pesquisa se não se demonstra habilidade escrita para compor exemplares deste gênero.

Connor e Mauranen (1999) se apropriaram do modelo de Swales (1990) para analisar movimentos retóricos recorrentes em projetos de pesquisa de pesquisadores sêniores na União Europeia, buscando identificar e descrever características do conhecimento convencionalizado de recursos linguísticos e discursivos nos projetos de 
pesquisa. A pesquisa de Connor e Mauranen (1999) é relevante por ser uma primeira tentativa de analisar a organização retórica de projetos de pesquisa, entretanto, as análises revelam certa confusão entre movimentos retóricos e seções de um gênero, a exemplo da nomeação que fazem da seção de Meios (ou metodologia) como se fosse um movimento quando, a rigor, a metodologia em projetos é uma seção configurada por vários movimentos e passos (MONTEIRO, 2016). Connor e Mauranen (1999) reconhecem a característica persuasiva que integra o propósito do gênero Projeto de Pesquisa (Grant Proposal, na terminologia em inglês) e explicitam a importância do ensino dos componentes retóricos e linguísticos de projetos de pesquisa como parte integrante da escrita em cursos acadêmicos.

Especificamente no que se refere à organização retórico-argumentativa da seção Justificativa, Jucá (2006) desenvolve trabalho em que analisa seções de Justificativa de projetos de dissertação já qualificados, de autoria de alunos de dois programas de pósgraduação a nível de mestrado de Fortaleza (CE) e descobriu que as seções de justificativa analisadas se mostravam relativamente homogêneas, havendo pouca divergência entre diferentes projetos quanto aos movimentos e passos retóricos (sub-unidades na terminologia usada por Jucá) mais recorrentes.

Em trabalho sobre Organização retórica da seção Justificativa de projetos de pesquisa de programas de pós-graduação, Alves Filho e Alexandre (2015) analisam as unidades retóricas que compõem a seção Justificativa de projetos de pesquisa ainda não qualificados de mestrandos de um programa de pós-graduação em Letras na cidade de Teresina (PI). Nesse sentido, elaboram uma classificação com esquemas de organização retórica que visam contemplar especificidades dos movimentos retóricos encontrados nos textos que compõem a amostra de sua pesquisa. Esse esquema, que indica os movimentos e passos da investigação, permite observar, além da organização retórica específica de cada grupo, possíveis influências da área de pesquisa na organização retórica da seção investigada.

\section{Metodologia}

O corpus da pesquisa é composto pelas seções de justificativa de 11 pré-projetos de pesquisa de mestrandos recém ingressos no curso de pós-graduação em História do 
Brasil da UFPI e de outros 11 pré-projetos de pesquisa de mestrandos recém ingressos no curso de pós-graduação em Letras/Linguística da UFPI, totalizando 22 seções de justificativa de pré-projetos de pesquisa. Os pré-projetos estão em sua versão original conforme enviados para o processo seletivo de pós-graduação, sem terem ainda sido lidos e revistos por orientadores.

Os pré-projetos de Linguística são aqui identificados pelas letras PL seguidos do número do projeto, enquanto os pré-projetos de História são identificados pelas letras $\mathrm{PH}$ seguidos do número do projeto. A escolha desse corpus teve como objetivo investigar a organização retórica que caracteriza a seção Justificativa em pré-projetos de pesquisa, observando, sobretudo, as sequências linguísticas que marcam a escrita acadêmica deste gênero nas áreas de História e Linguística, ambas vinculadas ao campo das ciências humanas, com o intuito de observar se há concepções diferentes acerca da organização retórica desta seção.

A partir do modelo CARS, elaborado por Swales (1990), que identifica três grandes movimentos e seus respectivos passos retóricos em introduções de artigos científicos de diversas áreas do conhecimento, e da proposta de Jucá (2006) para a seção Justificativa de pré-projetos de pesquisa de mestrandos da área de Linguística, Alves Filho e Alexandre (2015) propõem a adaptação desta estrutura retórica para analisar a seção de Justificativa em pré-projetos de pesquisa acadêmica, estabelecendo, para tanto, a redefinição de movimentos e passos retóricos, conforme o quadro abaixo: 
Quadro 1: Movimentos e passos retóricos em seção de Justificativa de projetos de pesquisa

\begin{tabular}{|c|c|}
\hline \multicolumn{2}{|c|}{ MOVIMENTOS E PASSOS RETÓRICOS } \\
\hline MOVIMENTO 1 (M1) & Indicando motivações deflagradoras da pesquisa \\
\hline Passo Retórico 1 (P1) & Reportando pesquisa prévia - M1P1 \\
\hline Passo Retórico 2 (P2) & Apresentando lacunas na área de pesquisa - M1P2 \\
\hline Passo Retórico 3 (P3) & Indicando problemas empíricos - M1P3 \\
\hline Passo Retórico 4 (P4) & $\begin{array}{l}\text { Alegando motivações pessoais/profissionais para a escolha } \\
\text { do tema - M1P4 }\end{array}$ \\
\hline MOVIMENTO 2 (M2) & Indicando caminhos norteadores da pesquisa \\
\hline Passo Retórico 1(P1) & Indicando os problemas/indagações da pesquisa - M2P2 \\
\hline Passo Retórico 2 (P2) & Declarando hipóteses da pesquisa - M2P2 \\
\hline Passo Retórico 3 (P3) & Apresentando objetivos da pesquisa - M3P3 \\
\hline MOVIMENTO 3 (M3) & Reivindicando a aplicabilidade/utilidade da pesquisa \\
\hline Passo Retórico 1 (P1) & $\begin{array}{l}\text { Justificando a relevância (teórica e/ou sócio-política) - } \\
\text { M3P1 }\end{array}$ \\
\hline Passo Retórico 2 (P2) & Indicando possíveis benefícios da pesquisa - M3P2 \\
\hline Passo Retórico 3 (P3) & Recomendando e/ou prescrevendo ação empírica - M3P3 \\
\hline MOVIMENTO 4 (M4) & Apoiando-se no campo teórico \\
\hline Passo Retórico 1 (P1) & Caracterizando a abordagem adotada - M4P1 \\
\hline Passo Retórico 2 (P2) & Justificando a adequação da teoria escolhida - M4P2 \\
\hline Passo Retórico 3 (P3) & $\begin{array}{l}\text { Historiando conceitos/categorias/abordagens da área de } \\
\text { pesquisa - M4P3 }\end{array}$ \\
\hline Passo Retórico 4 (P4) & Definindo conceitos - M4P4 \\
\hline Passo Retórico 5 (P5) & Explicando um fenômeno empírico \\
\hline Passo Retórico 6 (P6) & Apontando obras de referência para a pesquisa \\
\hline MOVIMENTO 5 (M5) & Indicando meios de realização da pesquisa \\
\hline Passo Retórico 1 (P1) & Justificando a escolha do corpus - M5P1 \\
\hline Passo Retórico 2 (P2) & Descrevendo o local da amostra - M5P2 \\
\hline Passo Retórico 3 (P3) & Descrevendo o corpus - M5P3 \\
\hline Passo Retórico 4 (P4) & $\begin{array}{l}\text { Indicar e/ou descrever os procedimentos de análise de dados } \\
\text { - M5P4 }\end{array}$ \\
\hline Passo Retórico 5 (P5) & Descrevendo procedimentos de análise dos dados - M5P5 \\
\hline
\end{tabular}


Com base no modelo de análise (Quadro 1), foram identificados, através de pistas linguísticas e do tratamento qualitativo dos dados, os movimentos e passos retóricos presentes em cada seção de Justificativa pesquisada. Cabe observar que, por vezes, o mesmo passo retórico repetiu-se em sentenças e parágrafos distintos ao longo dos textos, de modo que, em termos metodológicos, optou-se por registrar separadamente cada ocorrência dos passos retóricos em análise. Em seguida, as ocorrências de movimentos e passos retóricos encontrados nas 22 seções de Justificativa foram contabilizadas, a fim de se verificar, quantitativamente, quais são mais recorrentes em ambas as áreas.

Após a totalização dos registros encontrados, verificou-se em que medida os resultados expressam valores de cada uma das áreas em estudo, contrastando, em princípio, os três movimentos e passos retóricos predominantes nas seções de Justificativa em Linguística e História, e discutindo a ausência de determinados movimentos e passos retóricos nas seções em estudo. Buscou-se, ainda, identificar as similaridades na organização retórica das seções de Justificativa das duas áreas, com o propósito de refletir sobre a caracterização desta seção no gênero pré-projeto de pesquisa em práticas cotidianas de escrita.

Como estratégia para identificação dos movimentos e passos retóricos nas 22 seções de justificativa analisadas, foram observados marcadores léxico-gramaticais, sentenças e o conteúdo proposicional dos enunciados para verificar a possível ocorrência de 20 passos retóricos (ALVES FILHO; ALEXANDRE, 2015), que por sua vez estruturam os cinco movimentos já destacados (Movimento 1 - Indicando motivações deflagradoras da pesquisa; Movimento 2 - Indicando caminhos norteadores da pesquisa; Movimento 3 - Reivindicando a aplicabilidade/utilidade da pesquisa; Movimento 4 Apoiando-se no campo teórico; Movimento 5 - Indicando meios de realização da pesquisa). 


\section{Resultados e análises}

\section{Justificativa de pré-projetos da área de Letras/Linguística}

O Quadro 2 traz a compilação dos dados da área de Letras/Linguística:

Quadro 2: Quadro sinótico com movimentos e passos dos pré-projetos de Linguística

\begin{tabular}{|c|c|c|c|c|c|c|c|c|c|c|c|c|c|c|c|c|c|}
\hline & \multicolumn{4}{|c|}{$\begin{array}{l}\text { MOVIMENTO } \\
1\end{array}$} & \multicolumn{3}{|c|}{$\begin{array}{l}\text { MOVIMENTO } \\
2\end{array}$} & \multicolumn{2}{|c|}{\begin{tabular}{|l|} 
MOVIMENTO \\
3
\end{tabular}} & \multicolumn{4}{|c|}{$\begin{array}{l}\text { MOVIMENTO } \\
4\end{array}$} & \multicolumn{4}{|c|}{$\begin{array}{l}\text { MOVIMENTO } \\
5\end{array}$} \\
\hline & $\begin{array}{l}\mathrm{P} \\
1\end{array}$ & $\mathrm{P}$ & $\mathrm{P}$ & $\mathrm{P}$ & $\begin{array}{l}\mathrm{P} \\
1\end{array}$ & $\begin{array}{l}P \\
2\end{array}$ & $\begin{array}{l}P \\
3\end{array}$ & $\begin{array}{l}\mathrm{P} \\
1\end{array}$ & $\begin{array}{l}P \\
2\end{array}$ & $\begin{array}{l}\mathrm{P} \\
1\end{array}$ & $\mathrm{P}$ & $\begin{array}{l}\mathrm{P} \\
4\end{array}$ & $\begin{array}{l}P \\
5\end{array}$ & $\begin{array}{l}P \\
6\end{array}$ & $\mathrm{P}$ & $\mathrm{P}$ & $\begin{array}{l}\mathrm{P} \\
3\end{array}$ \\
\hline Quant. & 4 & 5 & 1 & 4 & 5 & 1 & 21 & 9 & 11 & 3 & 1 & 4 & 7 & 8 & 1 & 1 & 1 \\
\hline & \multicolumn{4}{|c|}{14} & \multicolumn{3}{|l|}{27} & \multicolumn{2}{|l|}{20} & \multicolumn{4}{|l|}{23} & \multicolumn{4}{|l|}{3} \\
\hline TOTAL & \multicolumn{17}{|l|}{87} \\
\hline
\end{tabular}

Ao examinar quantitativamente o Quadro 2, observa-se que os movimentos 2, 3 e 4 apresentam maior número de ocorrências. Dentre estes, dois passos se sobressaem numericamente em relação aos demais, são eles: o passo 3 do movimento 2 e o passo 2 do movimento 3.

No sentido macrocomposicional, os movimentos mais recorrentes, em ordem decrescente nas seções de justificativa dos pré-projetos de pesquisadores iniciantes em Letras/Linguística, são: Movimento 2 - Indicando caminhos norteadores da pesquisa; Movimento 4 - Apoiando-se no campo teórico e Movimento 3 - Reivindicando a aplicabilidade/utilidade da pesquisa. Os achados nos movimentos 1 e 5, por seu turno, em termos quantitativos, revelaram ser pouco significativos.

A partir da análise dos pré-projetos de Letras/Linguística investigados neste estudo, verificou-se, em linhas gerais, cinco passos que apresentam maior recorrência, listados a seguir: 
1. $\quad \mathrm{M}_{2} \mathrm{P} 3^{4}-$ Apresentando objetivos da pesquisa;

2. $\quad$ M3P2 - Indicando possíveis benefícios da pesquisa;

3. M3P1 - Justificando a relevância (teórica e/ou sócio-política) do projeto;

4. M4P6 - Apontando obras de referência para a pesquisa;

5. M4P5 - Explicando um fenômeno empírico.

“Apresentando objetivos da pesquisa” aparece como o passo retórico mais recorrente nos pré-projetos de Linguística. Foram registradas 21 ocorrências deste passo, o que parece evidenciar, levando-se em consideração a função da seção de justificativa, uma necessidade reiterada, por parte do autor, de demonstrar o que ele pretende realizar durante a pesquisa, acentuando os interesses teóricos e práticos que o motivam.

Os objetivos delimitam os interesses do pesquisador e, segundo Reis (2013, p. 84), “A escrita dos objetivos da pesquisa deve afirmar o que o autor/proponente quer com a pesquisa.”. Assim, ainda de acordo com a autora "ele pode querer: conhecer, entender, comparar, tecer crítica, descrever, identificar algo, (des)provar teoria, testar hipótese(s) etc.” (ibidem). Os objetivos seriam, então, proposições que visam, no futuro, concretizar uma ação. Na análise, tanto a frequência em que aparecem, quanto a ordem no texto não são fixas, ou seja, cada autor determina, usando critérios próprios, se apresentam os objetivos logo no início do texto ou no final, bem como se fazem uso desse passo por mais de uma vez na mesma seção. Essa possibilidade de escolha possibilita ao autor do pré-projeto dar ênfase a aspectos que ele considere mais relevantes.

Os exemplos a seguir ilustram como os autores geralmente fazem uso desse recurso:

Ex. 1: A partir disso, busca-se desenvolver uma proposta investigativa acerca do comportamento de ocorrências adjetivais na construção no valor modal apreciativo evidenciados nos enunciados do gênero jornal. (PL_16)

\footnotetext{
${ }^{4}$ A sigla M2P3, assim como todas as outras siglas apresentadas neste artigo, localiza o movimento e o passo retórico ao qual se faz referência, levando-se em conta o quadro apresentado na seção metodologia do respectivo artigo. Assim, lê-se M2P3: passo três do movimento dois.
} 
Ex. 2: [...] pretende-se, neste trabalho, investigar o tratamento da variação linguística em todos os verbetes de dicionários escolares, no intuito de proporcionar uma visão mais abrangente do fenômeno da variação linguística nesses materiais. (PL_24)

A combinação de duas formas verbais, busca-se desenvolver, pretende-se investigar, nos exemplos em destaque, explicitam claramente os objetivos norteadores de suas pesquisas, e, ainda que estes sejam obrigatórios em uma seção específica do préprojeto de pesquisa, sua recorrência na seção de justificativa revela ser de fundamental importância para os pesquisadores iniciantes em Letras/Linguística, os quais, ao demarcálos com ênfase nesta peça genérica, constroem a argumentação privilegiando, sobremaneira, os propósitos da investigação.

Os respectivos passos do Movimento 3, M3P2 - Indicando possíveis benefícios da pesquisa e M3P1 - Justificando a relevância (teórica e/ou sócio-política) do projeto, mostraram-se, logo em seguida, os mais recorrentes nas análises. Em conjunto, eles totalizaram 20 registros, demonstrando que os autores se preocupam em enfatizar que os resultados das pesquisas trarão contribuições para a sociedade e em particular para o mundo acadêmico.

O exemplo 3 ilustra como os autores expressam juízos de valor a respeito das contribuições de suas pesquisas:

Ex.3: Os resultados da pesquisa contribuirão para entendermos os valores que os moradores dão ao papel escrito e também à oralidade, sabendo que esses moradores têm as suas histórias, experiências e situações vividas que merecem ser resgatadas (BARTON; HAMILTON, 1998 apud LOPES, 2006). (PL_07)

No que respeita ao passo 1 do movimento 3, tem-se como exemplo o excerto abaixo:

Ex. 4: A partir da assimilação de tais conceitos, busca-se proporcionar por meio do método de ensino proposto nesta pesquisa uma melhor leitura e interpretação textual, bem como uma melhor escrita, ou seja, um conhecimento linguístico mais apurado. (PL_6) 
A utilização dos verbos contribuir, merecer, proporcionar constituem expressões que possuem forte componente persuasivo, na medida em que buscam convencer os avaliadores destes pré-projetos, através de sentenças afirmativas, que a aprovação destes trabalhos garantirá resultados positivos para o desenvolvimento científico e social.

Em terceiro lugar, os achados sobre o Movimento 4 e seus passos, M4P6 e M4P5, evidenciaram que os autores desta área também atribuem importância à utilização de elementos do campo teórico para validação dos seus pré-projetos de pesquisa. Somandose as ocorrências identificadas em ambos os passos, M4P6 e M4P5, que correspondem a 15 registros, percebe-se que os pesquisadores iniciantes valorizam mais especificamente estes dois passos do Movimento 4, uma vez que se reportar às obras de referência ou fornecer explicações sobre fenômeno empírico permite também a apropriação de argumentos de outros domínios discursivos, com o intuito de legitimar a aceitação da pesquisa junto à comunidade acadêmica. Os exemplos que seguem referem-se aos passos M4P6 e M4P5, respectivamente:

Ex. 5: Para este estudo serão utilizados os princípios teóricos e metodológicos de André (1995), Marcuschi (2005), Soares (1999, 2004), Tfouni (1997), Erickson (1988), dentre outros. (PL_01)

Ex. 6: Desde os estudos de Bakhtin houve um crescente interesse dos linguistas e outros estudiosos da língua acerca da necessidade de inserir o gênero textual no ensino de língua portuguesa como um eficiente meio para a compreensão da língua. (PL_16)

No trecho do exemplo 5, as referências às obras que tratam do objeto em estudo pelo autor são apresentadas diretamente, demonstrando que o desenvolvimento da futura pesquisa parte de um embasamento teórico-metodológico já discutido por escritores consagrados da comunidade especialista. No exemplo 6, apesar de ser feita uma alusão direta a um autor conhecido na área, não há necessariamente um aprofundamento dos conceitos discutidos pelo autor, tampouco uma fundamentação muito organizada acerca do que se afirma, de modo que o pesquisador iniciante formula este enunciado com base em reflexões mais gerais sobre este fenômeno, cristalizadas por certo senso comum 
acadêmico e apoiadas pela autoridade que o autor mencionado, Bakhtin, goza na área de linguística.

\section{Justificativa de pré-projetos da área de História}

Em relação às seções de justificativa dos pré-projetos dos mestrandos em História, o Quadro 3 sintetiza quantitativamente as ocorrências encontradas quanto aos movimentos e passos retóricos em estudo:

Quadro 3: Quadro sinótico com movimentos e passos dos pré-projetos de História

\begin{tabular}{|c|c|c|c|c|c|c|c|c|c|c|c|c|c|c|}
\hline & \multicolumn{2}{|c|}{$\begin{array}{l}\text { MOVIMENTO } \\
1\end{array}$} & \multicolumn{3}{|c|}{$\begin{array}{l}\text { MOVIMENTO } \\
2\end{array}$} & \multicolumn{2}{|c|}{$\begin{array}{l}\text { MOVIMENTO } \\
3\end{array}$} & \multicolumn{4}{|c|}{$\begin{array}{l}\text { MOVIMENTO } \\
4\end{array}$} & \multicolumn{3}{|c|}{\begin{tabular}{|l} 
MOVIMENTO \\
5
\end{tabular}} \\
\hline & $\begin{array}{l}P \\
2\end{array}$ & $\mathrm{P}$ & $\begin{array}{l}\mathrm{P} \\
1\end{array}$ & $\mathrm{P}$ & $\begin{array}{l}\mathrm{P} \\
3\end{array}$ & $\mathrm{P}$ & $\mathrm{P}$ & $\begin{array}{l}\mathrm{P} \\
1\end{array}$ & $\mathrm{P}$ & $\begin{array}{l}\mathrm{P} \\
5\end{array}$ & $\mathrm{P}$ & $\mathrm{P}$ & $\mathrm{P}$ & $\begin{array}{l}\mathrm{P} \\
3\end{array}$ \\
\hline Quant. & 11 & 9 & 1 & 1 & 18 & 6 & 2 & 6 & 2 & 8 & 7 & 2 & 1 & 4 \\
\hline & \multicolumn{2}{|l|}{20} & \multicolumn{3}{|l|}{20} & \multicolumn{2}{|l|}{8} & \multicolumn{4}{|l|}{23} & \multicolumn{3}{|l|}{7} \\
\hline
\end{tabular}

As totalizações destes registros mostram que os movimentos mais recorrentes nas seções de justificativa dos pesquisadores iniciantes em História são, em ordem decrescente: Movimento 4 - Apoiando-se no campo teórico; Movimento 1 - Indicando motivações deflagradoras da pesquisa e Movimento 2 - Indicando caminhos norteadores da pesquisa. Os movimentos 3 e 5, em relação aos outros, revelaram ser menos expressivos na escrita da peça genérica seção de justificativa dos mestrandos de História, que tratam de forma secundária a menção à aplicabilidade/utilidade da pesquisa, assim como os meios para realizá-la.

É importante observar ainda que, em relação ao Movimento 4, três de seus passos apresentam ocorrências numericamente similares e consistentes, o que demonstra um uso mais abrangente dos passos retóricos deste Movimento e, consequentemente, uma apropriação bastante regular dos recursos que expressam valorização do saber científico e acadêmico.

Seguindo ordem de maior recorrência, conforme os Quadros 2 e 3, estão listados a seguir os passos retóricos que apresentaram maior frequência nas análises: 
1. $\quad$ M2P3 - Apresentando objetivos da pesquisa;

2. M1P2 - Apresentando lacunas na área de pesquisa;

3. M1P4 - Alegando motivações pessoais/profissionais para a escolha do tema;

4. M4P5 - Explicando um fenômeno empírico.

Nas seções de justificativa dos mestrandos de História, destacou-se como mais recorrente o passo retórico “Apresentando objetivos da pesquisa”, doravante M2P3, o qual evidencia a necessidade reiterada de apontar as finalidades do projeto de pesquisa, conforme se vislumbra no exemplo abaixo:

Ex.7: Tendo isso em mente, a pesquisa em questão visa trazer novos elementos para a compreensão histórica dos papéis femininos, uma vez que as imagens fotográficas possibilitam o entendimento da produção de padrões estéticos associados à beleza feminina, levando em conta aspectos etários, de classe e etnia. (PH_01)

Aqui, a utilização da locução verbal visa trazer marca linguisticamente o passo retórico de apresentação de objetivos, uma vez que a combinação destes dois verbos (visa e trazer) sinaliza propósito futuro e ação concreta quanto à obtenção de resultados pretendidos (novos elementos para a compreensão histórica). Esta significativa recorrência sugere, por sua vez, que o passo retórico M2P3 assume centralidade na seção de justificativa dos pré-projetos de pesquisa dos mestrandos de História, secundarizando o papel de outros passos retóricos que também poderiam auxiliar na construção desta peça genérica.

Quanto ao passo M1P2 - Apresentando lacunas na área de pesquisa, especificamente nos pré-projetos da área de história, especula-se que seu uso, em quase todos os pré-projetos analisados, reflete o acento dado pelos pesquisadores iniciantes dessa área ao processo inicial de construção do conhecimento científico. Além disso, a apresentação de lacunas nos trabalhos é relativizada e modalizada no sentido de que, ao usarem esse recurso, os autores reconhecem que já há ações que podem ajudar a resolver o problema apresentado. A fim de ilustrar a relevância do passo M1P4 retratado no interior dos pré-projetos de história, reproduz-se, abaixo, alguns trechos que revelam a presença desses passos nos pré-projetos: 
Ex. 8: Apesar do cenário historiográfico sobre o tema estar se modificando, ainda há uma ausência significativa de estudos sobre as religiões de matriz africana no Piauí, fazendo com que haja a necessidade de dar voz a esse segmento da sociedade. (PH_04)

Ex. 9: Neste mês de agosto, a Revista Revestrés fez homenagem a ele com o título Possi: uma valsa piauiense. Fala-se muito em Possidônio Queiroz, mesmo assim existe muito espaço em branco. Seus documentos são um material, ainda, quase virgem ao olhar dos pesquisadores. (PH_05)

Ex. 10: Portanto, essa pesquisa é enriquecida e se singulariza pela carência de abordagens nos meios acadêmicos sobre a cidade de Teresina especificamente durante o período da noite, pelos objetivos intencionados aqui, poderá se fazer um paralelo interessante sobre os processos de mudanças de comportamento durante a noite da capital, perceber os hábitos de hoje em dia com um olhar nos hábitos de outrora. (PH_08)

Nos pré-projetos analisados também se verificou, dentre os mais utilizados pelos autores, o passo M1P4 - Alegando motivações pessoais/profissionais para a escolha do tema, também pertencente ao Movimento 1 - Indicando motivações deflagradoras da pesquisa, como se pode constatar nos exemplos a seguir:

Ex. 11: A ideia dessa pesquisa surgiu baseada em memórias pessoais, e por isso sentimentais, sobre estudar a noite na cidade de Teresina. Venho de uma família, que como muitas outras, transferiram-se do interior para a capital do Piauí em 1967, o motivo: a educação. (PH_08)

Ex. 12: O tema proposto tem como ponto de partida as discussões abordadas e não aprofundadas na elaboração do trabalho de conclusão de curso, como: características sociais e culturais das mulheres mais pobres da cidade, das feminilidades consideradas desviantes pelo sistema sócio-jurídico da cidade no referido período [...]. (PH_10) 
Nos exemplos 8, 9 e 10, os autores identificam claramente o campo pouco explorado de estudos sobre o qual a pesquisa pretende se debruçar, justificando, em seguida, a necessidade de empreender mais análises sobre o objeto escolhido. Ao todo, foram registradas 11 ocorrências do passo retórico M1P2, o que sinaliza uma preocupação reiterada dos mestrandos de História em delimitar os propósitos da investigação a partir de nichos acadêmicos ou empíricos que requeiram, de fato, mais estudos.

Os pesquisadores iniciantes dessa área, ao apontar explicitamente lacunas na produção científica, ressaltam, com efeito, as qualidades de trabalhos que já foram publicados e, ao mesmo tempo, os problemas que subjazem a essas publicações. De modo geral, os autores explicitam em suas afirmações com juízos de valor, buscando atribuir originalidade e inovação aos trabalhos que se propõem a realizar.

Quanto à recorrência do passo retórico M1P4, Alegando motivações pessoais/profissionais para a escolha do tema, totalizando 9 registros, é possível inferir que motivações pessoais, como relações de parentesco, predileções por autores e obras específicas, continuação de trabalhos iniciados anteriormente etc. colaboram para a escolha do objeto de estudo, além de influenciar os mestrandos a empreender suas pesquisas, como se observa nos exemplos 11 e 12, respectivamente. Ao relatar que “ $A$ ideia dessa pesquisa surgiu baseada em memórias pessoais [...]”, o mestrando de História insere elementos subjetivos no percurso da investigação, estabelecendo uma relação provavelmente mais comprometida, do ponto de vista pessoal, com o seu objeto de estudo.

De forma semelhante, no exemplo 10, o autor afirma que "O tema proposto tem como ponto de partida as discussões abordadas e não aprofundadas na elaboração do trabalho de conclusão de curso [...]”, ou seja, a necessidade de aprofundar as reflexões iniciadas em um trabalho anterior também tem como mote uma intencionalidade, neste caso, acadêmica do mestrando, que procura ressaltar, duplamente, a validade do tema abordado.

A presença do passo M4P5, Explicando fenômeno empírico, identificada através de 8 ocorrências, pode ser compreendida pelo excerto abaixo: 
Ex. 10: Era respeitada no meio em que viveu, seus livros foram traduzidos em outros idiomas e eram elogiados pela crítica em jornais da época. Em contrapartida, Nísia Floresta é quase desconhecida nos dias atuais. (PH_07)

Nota-se nesta passagem que o autor descreve, brevemente, os acontecimentos e contexto histórico que situam a proposta da pesquisa, apoiando-se em fontes bibliográficas que são genericamente citadas, sem uma referência explícita às publicações. Por meio de observações ou suposições, o mestrando conclui que a obra da escritora é desconhecida e daí reivindica a importância de investigá-la, tomando-a como objeto de sua pretensa pesquisa. A frequência deste passo retórico nas seções de Justificativa dos pré-projetos dos mestrandos de História, em conjunto com os registros dos demais passos retóricos do Movimento 4, Apoiando-se em campo teórico, implicam que os pesquisadores iniciantes da área privilegiam fortemente os dados e informações do campo acadêmico para estruturar estas peças genéricas.

O Quadro 4 traz os quantitativos comparando as ocorrências dos passos analisados nas duas áreas:

Quadro 4: Quadro sinótico comparativo com movimentos e passos dos pré-projetos de Linguística e História

\begin{tabular}{|c|c|c|c|c|c|c|c|c|c|c|c|c|c|c|c|c|c|}
\hline & \multicolumn{4}{|c|}{$\begin{array}{l}\text { MOVIMENTO } \\
1\end{array}$} & \multicolumn{3}{|c|}{$\begin{array}{l}\text { MOVIMENTO } \\
2\end{array}$} & \multicolumn{2}{|c|}{$\begin{array}{l}\text { MOVIMENTO } \\
3\end{array}$} & \multicolumn{5}{|c|}{$\begin{array}{l}\text { MOVIMENTO } \\
4\end{array}$} & \multicolumn{3}{|c|}{$\begin{array}{l}\text { MOVIMENTO } \\
5\end{array}$} \\
\hline & $\mathrm{P}$ & $\mathrm{P}$ & $\mathrm{P}$ & $\mathrm{P}$ & $\mathrm{P}$ & $\mathrm{P}$ & $\mathrm{P}$ & $\mathrm{P}$ & $\mathrm{P}$ & $\mathrm{P}$ & $\mathrm{P}$ & $P$ & $\mathrm{P}$ & $\mathrm{P}$ & $\mathrm{P}$ & $\mathrm{P}$ & $\mathrm{P}$ \\
\hline & 1 & 2 & 3 & 4 & 1 & 2 & 3 & 1 & 2 & 1 & 2 & 4 & 5 & 6 & 1 & 2 & 3 \\
\hline LING & 4 & 5 & 1 & 4 & 5 & 1 & 21 & 9 & 11 & 3 & 1 & 4 & 7 & 8 & 1 & 1 & 1 \\
\hline HIST & 0 & 11 & 0 & 9 & 1 & 1 & 18 & 6 & 2 & 6 & 2 & 0 & 8 & 7 & 2 & 1 & 4 \\
\hline
\end{tabular}

Tem-se, então, no Quadro 4, a configuração geral dos passos retóricos mais recorrentes e dos passos retóricos menos recorrentes nas duas áreas analisadas. Todos os pré-projetos da área de História apresentam o passo retórico M2P3 - Apresentando objetivos da pesquisa, enquanto, na área de linguística, 80\% dos pré-projetos contemplam o passo referido. Pode-se dizer, então, que para ambas as áreas, na seção de Justificativa, o passo relativo à apresentação dos objetivos destaca-se em relação aos demais, visto que pode ocorrer por mais de uma vez dentro da mesma seção. Este resultado indica que os 
objetivos são reconhecidos por estas duas comunidades acadêmicas como relevantes e valorativos na seção de Justificativa.

No corpus analisado, na área de Linguística, o passo M3P2 - Indicando possíveis benefícios da pesquisa, aparece como o segundo mais recorrente, divergindo numericamente com a área de História. Essa diferença pode indicar algum tipo de avaliação feita pelos candidatos, da área de Linguística, sobre a necessidade de convencer os leitores apontando os benefícios sociais e práticos da pesquisa. Nesse recorte na área de Letras, o caráter aplicado da pesquisa aparece como um valor importante.

Vê-se, no passo M1P2 - Apresentando lacunas na área de pesquisa, especificamente na área de História, a importância dada pelos mestrandos às lacunas deixadas por outros trabalhos e o mister de, mesmo que parcialmente, resolver o problema ou as lacunas de pesquisa. Diferentemente da área de Linguística em que os mestrandos parecem querer atenuar problemas da vida social com suas pesquisas. A avaliação pode ser reforçada quando se compara os números do Quadro 4 e se percebe a predileção da área de Linguística pela indicação dos possíveis benefícios que a pesquisa pode trazer. A tendência geral é esta: as justificativas em História apegam-se a uma avaliação de um déficit de pesquisa no passado, enquanto em Letras/Linguística, as justificativas se fundam em possíveis aplicações futuras dos resultados da pesquisa.

Em contrapartida, os passos M1P3 - Indicando problemas empíricos, M2P2 Declarando hipóteses da pesquisa, M4P2 - Justificando a adequação da teoria escolhida, M5P1 - Justificando a escolha do corpus, M5P2 - Descrevendo o local da amostra e M5P3 -Descrevendo o corpus apresentam-se como os menos recorrentes em ambas as análises. Tais resultados próximos de uma ocorrência podem indicar que esses passos, para a organização retórica da seção de Justificativa em pré-projetos de mestrado nas áreas de Linguística e História, não são considerados essenciais na estrutura dessas seções.

Em termos comparativos, obteve-se que “Apresentando objetivos da pesquisa” é o passo retórico mais expressivo no corpus analisado. Nos pré-projetos de Letras/Linguística foram verificadas 21 ocorrências e nas seções de justificativa dos mestrandos de História contabilizou-se 18 registros. Estas são duas áreas que pertencem ao campo das ciências humanas e esses dados sugerem que os pesquisadores iniciantes de Linguística e História atribuem um valor significativo às metas que pretendem alcançar 
através destas investigações, por reiteradas vezes. Provavelmente, o uso deste recurso se constitua como estratégia de persuasão, uma vez que os autores pretenderiam demonstrar para a instituição acadêmica que os seus propósitos são bem definidos e exequíveis.

No que diz respeito ao caminho escolhido para estruturar a seção de justificativa de pré-projetos de pesquisa, percebeu-se que os mestrandos de História optam, sobretudo, por organizar esta peça genérica a partir do levantamento de problemas, haja vista a recorrência do passo M1P2 - Apresentando lacunas na área de pesquisa, com 11 registros identificados. Os pesquisadores iniciantes de Letras/Linguística, por outro lado, preferiram destacar os resultados positivos que suas investigações poderão trazer para a sociedade e a comunidade acadêmica, o que se evidencia através dos passos M3P2 Indicando possíveis benefícios da pesquisa, com 11 ocorrências, e M3P1 - Justificando a relevância (teórica e/ou sócio-política) do projeto, por 9 vezes registrado.

Além de problematizar a realidade, buscando instaurar novos percursos investigativos, os mestrandos de História também apresentaram razões de ordem subjetiva, como ponto de partida, para a elaboração dos seus pré-projetos. O passo M1P4 - Alegando motivações pessoais/profissionais para a escolha do tema, foi contabilizado 9 vezes nas seções de justificativa desta área, ao passo que nos pré-projetos de Linguística ele recorre apenas em 4 registros.

De forma similar, mestrandos das duas áreas também fazem uso do passo M4P5 - Explicando um fenômeno empírico, 7 registros em Linguística e 8 nas seções de justificativa de História, indicando que a descrição do fenômeno a ser analisado, com alusões mais genéricas sobre teorias e conhecimentos produzidos acerca deste objeto, é um elemento que se apoia em discursos socialmente instituídos, conferindo legitimidade à proposta de investigação.

Nossa pesquisa chegou a resultados um tanto diferentes daqueles encontrados por Jucá (2006), já que este autor descobriu que as seções de justificativa analisadas se mostravam relativamente homogêneas. Já em nosso corpus houve um grau acentuado de heterogeneidade entre projetos de cada subárea e, mais ainda, quando comparamos as duas subáreas. 


\section{Considerações finais}

A comparação entre os passos retóricos mais recorrentes nas duas áreas mostra que há uma convergência quanto ao valor que desfruta o ato de comunicar os objetivos da pesquisa. No universo de análise, predomina a ideia de que uma justificativa de uma pesquisa se assenta claramente sobre os objetivos a que ela se propõe, com o passo “Apresentando objetivos da pesquisa” respondendo pelo núcleo definidor da seção. Esta centralidade dos objetivos encontra ressonância no fato de que, a despeito de haver uma seção específica do projeto para a apresentação dos objetivos, estes aparecem reiterados, no caso da área de Linguística, ainda nas seções de metodologia e de fundamentação teórica.

Quanto aos demais passos, há mais divergência que convergência entre as duas áreas. Na Linguística, valora-se bastante a indicação de benefícios e da relevância da pesquisa, o que demonstra preocupação com possíveis aplicações da pesquisa e com aspectos que possam mostrar seu vínculo com a realidade sócio-política. Em História, valora-se mais acontecimentos do passado, ou no campo da pesquisa, como as lacunas de pesquisa na área, ou no campo pessoal, como motivações pessoais/profissionais do pesquisador. As justificativas de Linguística olham para problemas a serem sanados no futuro através dos eventuais benefícios da pesquisa, ao passo que as justificativas de História olham para o que deixou de ser feito no passado em termos de pesquisa ou de realização do pesquisador. Em Linguística, a justificativa tende a decorrer de problemas do mundo real; em História, de problemas do mundo da pesquisa.

Agradecimentos: Ao Conselho Nacional de Desenvolvimento Científico e Tecnológico, por intermédio do Edital Universal 2014, e à Universidade Federal do Piauí, através do Edital de Bolsa de Produtividade.

ALVES FILHO, Francisco; OLIVEIRA, Meryane Sousa. The rhetorical organization of Justification sections of research pre-projects. Revista do Gel, v. 14, n. 1, p. 36-58, 2017. 


\begin{abstract}
This paper aims to identify and describe, through linguistics clues and textual organization, the rhetorical organization of the Justification section of the pre master's project genre of the Graduate Programs in Linguistics and History of Brazil of Universidade Federal do Piauí - UFPI, submitted to selection in 2015, seeking to identify if there are singularities in each of them. The analysis was done with the use of the approaches proposed by Swales (1990), Alves Filho e Alexandre (2015) and Jucá (2006). 11 pre master's project researches were selected from the graduate course in History of Brazil and 11 pre master's project researches were selected from the graduate course in Linguistics of UFPI, totalizing 22 justification sections. In general, the results indicate that Presenting research objectives is the most significant rhetorical step in the corpus of the two analyzed areas. Furthermore, it was possible to verify that master's degree students in History choose, overall, to organize that generic piece from surveying problems, while beginners master's degree students in Linguistics, on the other hand, preferred to highlight the positive results that their investigations may bring to society and the academic community.
\end{abstract}

Keywords: Research Genres. Rhetoric organization. Justification Section. Pre-project.

Submetido em: 23/04/2016.

Aceito em: 31/08/2016.

\title{
Referências
}

ALVES FILHO, F.; ALEXANDRE, L. R. B. Organização retórica da seção de justificativa de projetos de pesquisa de programas de pós-graduação. In: Simpósio Internacional de Estudos de Gêneros Textuais, 8, 2015, São Paulo. Anais... São Paulo: 2015, p. 814-815.

ASKEHAVE, I.; SWALES, J. M. Identificação de gênero e propósito comunicativo: um problema e uma possível solução. In: BEZERRA, B. G.; BIASI-RODRIGUES, B.; CAVALCANTE, M. M. (Org.). Gêneros e sequências textuais. Recife: Edupe, 2009. p. 221-243.

BERNARDINO, C. G. Depoimentos dos alcóolicos anônimos: um estudo do gênero textual. 2000. 163 f. Dissertação (Mestrado em Linguística) - Centro de Humanidades, Universidade Federal do Ceará, Fortaleza, 2000.

BEZERRA, B. A distribuição das informações em resenhas acadêmicas. 2001. 141 f. Dissertação (Mestrado em Linguística) - Centro de Humanidades, Universidade Federal do Ceará, Fortaleza, 2001.

BIASI-RODRIGUES, B. O gênero resumo: uma prática discursiva da comunidade acadêmica. In: BIASI-RODRIGUES, B.; ARAÚJO, J.; SOUSA, S. (Org.). Gêneros textuais e comunidades discursivas: um diálogo com John Swales. Belo Horizonte: Autêntica Editora, 2009. p. 49-75. 
BIASI-RODRIGUES, B.; HEMAIS, B. A proposta sociorretórica de John M. Swales para o estudo de gêneros textuais. In: MEURER, J. L.; BONINI, A.; MOTTA-ROTH, D. (Org.) Gêneros: teorias, métodos, debates. São Paulo: Parábola Editorial, 2005. p. 108129.

CONNOR, U.; MAURANEN, A. Linguistic Analysis of Grant Proposals: European Union Research Grants. Pergamon, v. 18, p. 47-62, 1999. Disponível em:

<www.researchgate.net/.../222022829 $>$. Acesso em: 15 out. 2015.

DEVITT, A. J. Writing genres. Carbondale: Southern Illinois University Press, 2004.

JUCÁ, D. C. N. A organização retórico-argumentativa da seção de justificativa no gênero textual projeto de dissertação. 2006. 109 f. Dissertação (Mestrado em Linguística) - Centro de Humanidades, Universidade Federal do Ceará, Fortaleza. 2006.

MILLER, C. R. Estudos sobre: gênero textual, agência e tecnologia. DIONÍSIO, A. P.; HOFFNAGEL, J. C. (Org.). Tradução e adaptação de Judith Chambliss Hoffnagel et al. Recife: Ed. Universitária da UFPE, 2009.

MONTEIRO, B. N. Organização retórica e estruturação sequencial da seção de metodologia do gênero projeto de pesquisa. 2016. 162 f. Dissertação (Mestrado em Letras) - Centro de Ciências Humanas e Letras, Universidade Federal do Piauí, Teresina. 2006.

MOTTA-ROTH, D.; HENDGES, G. R. Uma análise transdisciplinar do gênero abstract. Intercâmbio, 7, p. 125-134, 1998. <www.ufsm.br/labler/publi/anlise.htm>. Acesso em: 27 dez. 2015.

REIS, S. Passos para projeto de pesquisa. Revista X, v. 1, p. 81-95, 2013. <ojs.c3sl.ufpr.br/ojs/index.php/revistax/article/viewFile/33535/21401>. Acesso em: 15 out. 2015.

SOUSA, S. Estudo da organização textual-argumentativa em editoriais de jornal. 2004. 141 f. Dissertação (Mestrado em Linguística) - Centro de Humanidades, Universidade Federal do Ceará, Fortaleza, 2004.

SWALES, J. Genre analysis - English in academic and research settings. Cambridge: Cambridge University Press, 1990.

Research Genres - Explorations and Applications. Cambridge University Press, 2004. p. 207-240. 